The Journal of Animal \& Plant Sciences, 31(3): 2021, Page: 657-664

ISSN (print): 1018-7081; ISSN (online): 2309-8694

\title{
EFFICACY OF ESTRUS SYNCHRONIZATION PROTOCOLS IN NON-DESCRIPT CATTLE OF AZAD JAMMU AND KASHMIR DURING NON-BREEDING AND BREEDING SEASONS
}

\author{
B. Shahid ${ }^{1}$, M. I. Khan ${ }^{2}$, S. M. H. Andrabi ${ }^{3}$ and M. N. Khan ${ }^{1}$ \\ ${ }^{1}$ Department of Zoology, University of Azad Jammu and Kashmir, Muzaffarabad, Pakistan. \\ ${ }^{2}$ Livestock Development Research Centre, Muzaffarabad, Azad Jammu and Kashmir. \\ ${ }^{3}$ Animal Reproduction Laboratory, Animal Sciences Institute, National Agricultural Research Centre, Park Road, \\ Islamabad, Pakistan. \\ Corresponding Author's E mail: beenishkhan124@gmail.com
}

\begin{abstract}
The objective of the present study was to compare the efficacy of estrus synchronization protocols through estrus response and fertility rate in non-descript cattle of Azad Jammu and Kashmir during the non-breeding and breeding seasons. A total of 312 non-descript cows (192) and heifers (120) with body condition score ranging between 3.0 to 3.5 were randomly assigned to receive Ovsynch (159), CIDR alone (74) and CO-Synch+CIDR (79) protocols. Animals were inseminated at $16 \mathrm{~h}$ after the second GnRH injection in Ovsynch, and $48 \mathrm{~h}$ after CIDR removal in CIDR alone and COSynch+CIDR groups. The results revealed that during non-breeding season, the tendency for success of the Ovsynch protocol was higher in terms of inducing heat and conception rate (CR) in non-descript cows under farm (87.5\%) and field $(50.0 \%)$ conditions compared to CIDR alone and CO-Synch+CIDR groups $(\mathrm{P}<0.05)$. Whereas, in the case of nondescript heifers, the CO-Synch+CIDR protocol significantly increased the CR at timed artificial insemination (TAI) under farm (50.0\%) and field (33.33\%) conditions compared to Ovsynch and CIDR alone groups $(\mathrm{P}<0.05)$. During the breeding season, CR/TAI was almost similar in all groups of non-descript cows under field conditions $(\mathrm{P}>0.05)$. COSynch+CIDR treatment yielded the higher conception rates $(46.15 \%)$ in non-descript heifers compared to Ovsynch and CIDR alone groups. It is concluded that treatment of cows with Ovsynch, and heifers with CO-Synch+CIDR protocols may lead to higher CR/TAI and thus have the potential to improve the reproductive performance that can accelerate the rate of genetic improvement through AI.
\end{abstract}

Key words: Fertility, breeding season, estrus synchronization, non-descript cattle.

https://doi.org/10.36899/JAPS.2021.3.0255

Published online November 09,2020

\section{INTRODUCTION}

In sub-tropical highland environment of Azad Jammu and Kashmir (AJ\&K) the non-descript cattle are of zebu type. These cattle attain puberty at greater age and have low productive potential attributed to their poor genetic makeup (Khan et al., 2014). Poor artificial insemination services enhance postpartum infertility problems in cattle. Several other factors such as quality of semen, poor nutrition, reproductive health, estrus behavior and detection of proper heat also contribute to poor reproductive performance (Anzar et al., 2003; Senthilkumar and Chandrahasan, 2015).

In cattle, the consideration of a defined breeding season is an important reproductive management strategy. The Bos indicus and crossbred cows of Bos indicus are long day breeders. Numerous reports are available in the literature that reproductive function is suppressed with decrease in day length in Bos indicus cattle (Randel, 1984). During unfavorable seasons, the Bos indicus tend to become anestrus and the frequency of estrus without ovulation also increased in Bos indicus females (Plasse et al., 1970). Lower progesterone concentrations were reported in heifers during the months of November, December, January and February than in either October or March (Stahringer et al., 1999). In order to overcome seasonality of breeding, a synchronization protocol should initiate follicular development by the activating hypothalamo-ovarian axis.

Estrus synchronization and fixed-time AI protocols such as Ovsynch, CIDR alone and COSynch+CIDR have been developed to decrease reliance on detection of estrus in reproductive management programmes to establish sustainability in the dairy industry (Bhoraniya et al., 2012; Nakrani et al., 2014). The Ovsynch protocol is a sequence of GnRH - PGF2 $\alpha$ GnRH treatments that became popular for estrus synchronization in cattle over the last decade, resulting in an acceptable fertility to timed AI (Pursley et al., 1997a). Numerous variations of the protocol have also been tested and developed to meet demands of different physiological situations (Stevenson et al., 2012). The CIDR alone protocol involves the use of an internal progesterone releasing device placed in the vagina of an 
animal on day 0 for 5-9 d (Mapletoft et al., 2003; Haider et al., 2017). The CIDR device with GnRH and PGF $2 \alpha$ may provide a more efficient protocol of improving the fertility e.g., CO-Synch+CIDR (Lamb et al., 2001) in non-cycling postpartum cows and heifers before puberty (Lamb et al., 2006). CO-Synch+CIDR protocol has been reported to produce conception rates at first service averaging more than 50\% (Lamb et al., 2001) in Bos taurus cows.

In zebu cattle including the non-descript cows limited information is available about the efficacy of estrus synchronization for induction of heat and enhancing pregnancy per AI (Haider et al., 2017) and such studies have been conducted in canal irrigated areas of Punjab Pakistan. However, no such study is available on indigenous cattle of AJ\&K. Therefore, the objectives of this study were to determine the estrus response and conception rates with estrus synchronization protocols during non-breeding and breeding seasons in non-descript indigenous cattle for the rapid genetic through grading up.

\section{MATERIALS AND MEHODS}

Animals and Management: During the non-breeding season (October-March 2016-17) 103 non-descript cows out of which 27 at farm and 76 in field of mixed parity that had calved between 60-540 days ago and 68 heifers out of which 16 at farm and 52 in field between 3 and 4 years of age with body condition score ranges between 3.0 to 3.5 were selected (Wildman et al., 1982). The farm trial was conducted at the Livestock Development Research Centre (LDRC), Muzaffarabad (34.361 ${ }^{\circ} \mathrm{N}$ and $\left.73.662^{\circ} \mathrm{E}\right)$. All the animals at farm were stall fed on Total Mixed Ration (TMR; Big Feed Pvt. Ltd Pakistan at the rate of $2 \%$ body weight) with adequate supply of fresh, clean and soft drinking water under the same management and environmental conditions. The ration was calculated to provide the recommended quantity of nutrients (Table 1). Common salt in the form of lump was placed in feeding pan and cows were free to lick. The field trial was conducted in northern districts of Azad Jammu and Kashmir viz. Muzaffarabad and Bagh districts. The topography of the Muzaffarabad and Bagh districts is mountainous, and the area falls within the lesser Himalayas zone. Under field conditions, during the summer months, the feeding of the animal is only the open grazing of grass and forage whereas, in winter months the animals are kept tied on the manger and hay is offered for feeding ad libitum. Only the milking cows are being fed with 1-1.5 kg of concentrate per day.

All the animals were randomly selected regardless of the stage of estrous cycle with body condition score ranging between 3.0 to 3.5, without any reproductive problem. Body condition-score (BCS) 1 for very thin 2 for thin 3 for moderate, 4 for optimal and 5 for very fat.

During the breeding season (April-September $2017)$, the lactating non-descript cows $(n=89)$ and heifers $(\mathrm{n}=52)$, maintained by farmers under field conditions in Muzaffarabad and Bagh districts were utilized in this study. Cows included in this study were non-pregnant, having age between $4-8$ years, $1^{\text {st }}$ to $4^{\text {th }}$ lactation, minimum 60 days postpartum and BCS ranges from 3.0 to 3.5 (Wildman et al., 1982). During summer months, the feeding of the animal is confined to the open grazing of grass and forage. The animals with normal history of calving were included in this study and were rectally palpated to ensure that the reproductive tract had no abnormality.

Protocols: Three protocols were utilized in 192 cows and 120 heifers for synchronization of estrus viz. Ovsynch (105 cows, 54 heifers), CIDR alone (43 cows, 31 heifers) and CO-Synch+CIDR (44 cows, 35 heifers). In the Ovsynch group, all the cows and heifers were injected with $100 \mathrm{ug}$ of GnRH analogue (Dalmarelin; lecirelin acetate $25 \mathrm{ug} / \mathrm{ml}$, FATRO S.p.A.-pharmaceutical veterinary Industry, Italy) on day $0,25 \mathrm{mg}$ of PGF $2 \alpha$ (Lutalyse $^{\mathrm{TM}}$, Dinoprost tromethamine $5 \mathrm{mg} / \mathrm{ml}$, Pfizer manufacturing Belgium NV- Puurs- Belgium) on day 7 and $2^{\text {nd }}$ injection of GnRH on day 9. In the CIDR alone group, the progesterone impregnated device (1.38 $\mathrm{g}$ of progesterone, Pfizer New Zealand Ltd) were placed in the vagina of all the cows on day 0 , on day 7 PGF $2 \alpha$ were administered and the CIDRs were removed. In COSynch+CIDR group, the CIDRs were inserted intravaginally and GnRH analogue was administered on d 0 . At $d$ 7, CIDR were removed and cows received PGF2 $\alpha$. On d 9 the second GnRH injection was administered.

Animals were evaluated for estrus behavior expression 3 times daily at $8 \mathrm{~h}$ intervals. Estrus expression was conducted based on cardinal signs (mucous discharge, vulvar swelling, micturition, restlessness, bellowing sound, mounting, redness of vaginal mucosa, sniffing, chin resting, aggression, including standing heat as a primary sign of heat) with some modification in the format described by Layek et al. (2011). Fixed-time AI (FTAI) was performed by an experienced AI technician at $16 \mathrm{~h}$ after second $\mathrm{GnRH}$ administration in Ovsynch treatment and $48 \mathrm{~h}$ after CIDR removal in all CIDR treated animals using the frozen thawed semen of Jersey bulls. The schematic representation is presented in Fig. 1(a,b,c). Estrus response (ER) was calculated by dividing the cows in heat over total cows treated. Conception was confirmed through rectal palpation 60 days post-AI. The animals that showed spontaneous heat were observed closely especially from 18 to 24-day post AI and were reinseminated. Conception rate $(\mathrm{CR})$ was calculated by 
total number of pregnant cows or heifers divided by total number of cows or heifers inseminated multiplied by 100 (Khatun et al., 2014).

Statistical Analysis: Chi-square $\left(\chi^{2}\right)$ tests of independence were used to compare the estrus response and conception rates among different groups of animals treated with different estrus synchronization protocols. A probability level of $\mathrm{P}<0.05$ was considered significant. All the data were analyzed using GraphPad Prism 5.01 software (GraphPad Software, Inc., San Diego, CA, USA).

\section{RESULTS}

ER and CR in Non-Descript Cows During NonBreeding Season: The heat response in terms of heat signs under farm conditions was $100 \%$ in Ovsynch and CO-Synch+CIDR groups and $87.5 \%$ in CIDR alone group as shown in Table 2. Conception rate at TAI tended to be higher in the Ovsynch group (87.5\%) compared to CIDR alone (50.0\%) and CO-Synch+CIDR $(54.54 \%)$ groups but this difference was non-significant $(\mathrm{P}>0.05)$. Similarly, the overall maximum conception rate $(100 \%)$ was achieved by the treatment with Ovsynch compared to CIDR alone $(75.0 \%)$ and CO-Synch+CIDR $(90.90 \%)$ groups but this difference was also nonsignificant $(\mathrm{P}>0.05)$.

After applying prostaglandin, $95.45 \%$ of Ovsynch treated cows were found in estrus under field conditions, with this percentage being similar in CIDR inserted animals in which estrus manifestation was $88.88 \%$ and $92.85 \%$ in CIDR alone and COSynch+CIDR cows, respectively. Although, a higher trend of conception rate at TAI $(50.0 \%)$ and overall conception rate $(63.63 \%)$ was observed in the Ovsynch group but this did not differ $(\mathrm{P}>0.05)$ among treatments (Table 2). Statistical analysis also showed that conception rate with Ovsynch treatment was significantly $(\mathrm{P}=0.04)$ higher under farm conditions as compared to field conditions (Table 3).
ER and $C R$ in Non-Descript Heifers During NonBreeding Season: All the heifers treated with three protocols showed good signs of heat at the time of fixed time insemination under farm conditions. The results revealed that the $\mathrm{CO}-\mathrm{Synch}+\mathrm{CIDR}$ protocol showed higher tendency $(\mathrm{P}>0.05)$ in the conception rate in nondescript heifers under farm conditions (Table 4). Under field conditions after the application of prostaglandin, synchronized estrus response was $95.45 \%, 91.66 \%$ and 94.44\% in Ovsynch, CIDR alone and CO-Synch+CIDR treated heifers, respectively and did not differ significantly $(\mathrm{P}>0.05)$. However, in all the 52 animals insemination was performed at a fixed time. Although a higher trend of conception rate to TAI was observed in the CO-Synch+CIDR group (33.33\%) but this difference was not significant $(\mathrm{P}>0.05)$ between treatments (Table 4). The statistical analyses of this study revealed that the conception rates did not differ significantly $(\mathrm{P}>0.05)$ by three treatment groups under farm conditions compared to field conditions in non-descript heifers (Table 5).

ER and CR in Non-Descript Cows and Heifers During Breeding Season: During the breeding season, all the non-descript cows showed good signs of heat at the time of insemination. Although, the tendency of overall pregnancy was higher in the CO-Synch+CIDR (57.89\%) cows compared to Ovsynch (54.71\%) and CIDR alone $(52.94 \%)$ but the conception rates to a single FTAI were not significantly different $(\mathrm{P}>0.05)$ between groups under field conditions as given in Table 6. Similarly, all the heifers also showed good signs of heat at the time of insemination in the Ovsynch $(100 \%)$, CIDR alone $(85.71 \%)$ and CO-Synch+CIDR $(100 \%)$ groups $(\mathrm{P}>0.05)$. The trend for conception rate to TAI (46.15\%) and overall pregnancy rate $(53.84 \%)$ was superior in COSynch+CIDR group but difference was not significantly different compared to other two groups $(\mathrm{P}>0.05)$. The $\mathrm{CO}-\mathrm{Synch}+\mathrm{CIDR}$ protocol may prove to be a successful tool for synchrony of estrus in non-descript heifers compared to other treatments during the breeding season (Table 6). 
a)

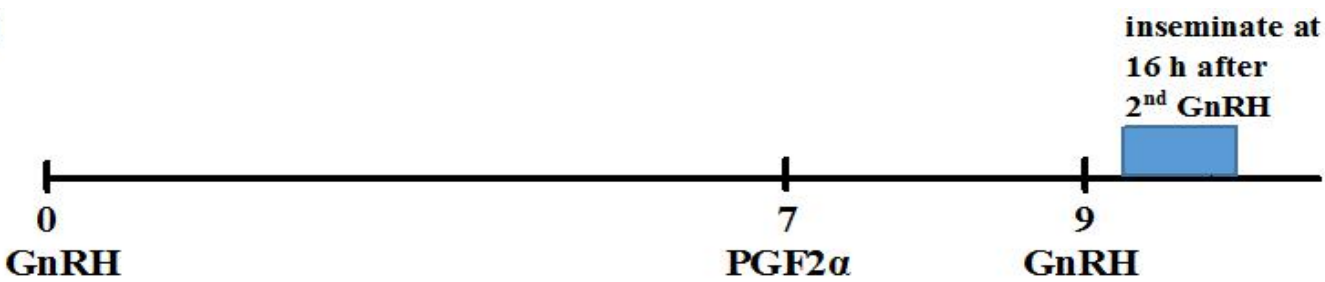

b)

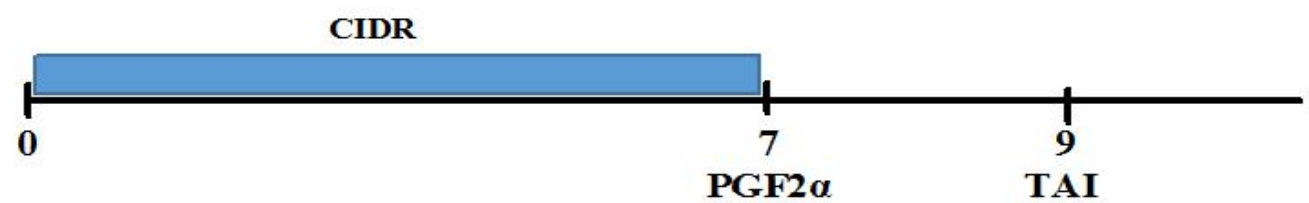

c)

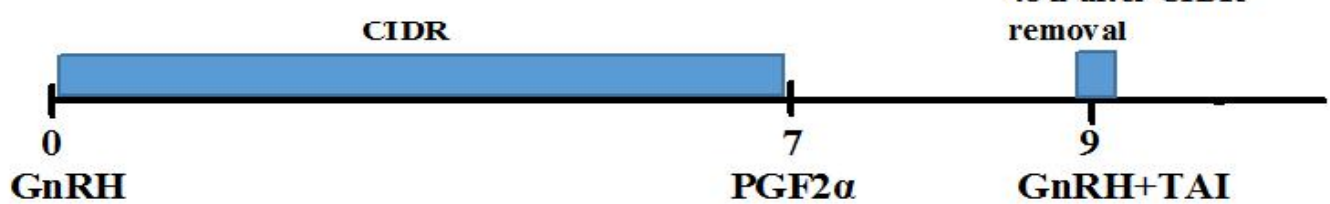

Figure 1. The schematic representation of estrus synchronization protocols a) Ovsynch, b) CIDR alone, c) COSynch+CIDR.

Table 1: Daily quantity of nutrient fed to cows according to their status weighing $250 \mathrm{~kg}$ body weigh

$\mathrm{DM}=$ Dry Matter; TDN = Total Digestible Nutrient $\mathrm{CP}=$ Crude Protein $; \mathrm{Ca}=$ Calcium; $\mathrm{P}=$ Phosphorous; Kg $=$ Kilogram.

\begin{tabular}{|c|c|c|c|c|c|}
\hline \multirow[b]{2}{*}{ Status } & \multirow{2}{*}{$\begin{array}{c}\text { Total Dry Matter } \\
(\text { Kg) }\end{array}$} & \multicolumn{4}{|c|}{ Type of Nutrients (Kg) } \\
\hline & & TDN & $\mathbf{C P}$ & Ca & $\mathbf{P}$ \\
\hline Early Lactation & 5.955 & 3.525 & 0.625 & 0.02 & 0.01 \\
\hline Lactating and Pregnant & 5.705 & 3.135 & 0.495 & 0.015 & 0.01 \\
\hline Dry Non-Pregnant & 4.205 & 2.115 & 0.3 & 0.01 & 0.005 \\
\hline $\begin{array}{l}\text { Pre-Calving } \\
\text { (60-90 days before calving) }\end{array}$ & 5.16 & 2.795 & 0.44 & 0.015 & 0.01 \\
\hline
\end{tabular}

Table 2. Estrus response and conception rate $(\%)$ of non-descript cows in which time of estrus was synchronized with the Ovsynch, CIDR alone and CO-Synch+CIDR protocols during non-breeding season under controlled conditions at LDRC and field conditions.

\begin{tabular}{|c|c|c|c|c|c|c|}
\hline Treatment & $\begin{array}{c}\text { No. } \\
\text { of } \\
\text { Cows }\end{array}$ & $\begin{array}{c}\text { Estrus } \\
\text { Response }\end{array}$ & $\begin{array}{c}\text { CR at } \\
\text { TAI (\%) }\end{array}$ & $\begin{array}{l}\text { Animals showed heat } \\
\text { after } 21 \text { d and were } \\
\text { served again }(\%)\end{array}$ & $\begin{array}{c}\text { CR after } \\
2^{\text {nd }} \text { service }\end{array}$ & $\begin{array}{c}\text { Overall CR } \\
\text { after two } \\
\text { services (\%) }\end{array}$ \\
\hline \multicolumn{7}{|c|}{ Farm } \\
\hline Ovsynch & 8 & $8(100)$ & 7 (87.5) & 1 & $1(12.5)$ & $8(100)$ \\
\hline CIDR alone & 8 & $7(87.5)$ & $4(50.0)$ & 2 & $2(25.0)$ & $6(75.0)$ \\
\hline $\begin{array}{l}\text { CO-Synch } \\
+ \text { CIDR }\end{array}$ & 11 & $11(100)$ & $6(54.54)$ & 4 & $4(36.36)$ & $10(90.90)$ \\
\hline \multicolumn{7}{|c|}{ Field } \\
\hline Ovsynch & 44 & $42(95.45)$ & $22(50.0)$ & 8 & $6(13.63)$ & $28(63.63)$ \\
\hline CIDR alone & 18 & $16(88.88)$ & $5(27.77)$ & 6 & $6(33.33)$ & $11(61.11)$ \\
\hline $\begin{array}{l}\text { CO-Synch } \\
+ \text { CIDR }\end{array}$ & 14 & $13(92.85)$ & $5(35.71)$ & 3 & $2(14.28)$ & $7(50.0)$ \\
\hline
\end{tabular}


Table 3. Comparison of conception rate at TAI between farm and field conditions during non-breeding season in non-descript cows.

\begin{tabular}{|c|c|c|c|c|}
\hline \multirow{2}{*}{ Treatment } & \multicolumn{2}{|c|}{ CR at TAI in cows (\%) } & \multirow{2}{*}{ Chi sq value } & \multirow{2}{*}{$P$ value } \\
\hline & Farm & Field & & \\
\hline Ovsynch & 87.5 & 50.0 & 3.85 & 0.04 \\
\hline CIDR alone & 50.0 & 27.77 & 1.20 & 0.27 \\
\hline CO-Synch+CIDR & 54.54 & 35.71 & 0.88 & 0.34 \\
\hline
\end{tabular}

Table 4. Estrus response and conception rate (\%) of non-descript heifers in which time of estrus was synchronized with the Ovsynch, CIDR alone and CO-Synch+CIDR protocols during non-breeding season under controlled conditions at LDRC and field conditions.

\begin{tabular}{|c|c|c|c|c|c|c|}
\hline Treatment & $\begin{array}{l}\text { No. of } \\
\text { Heifers }\end{array}$ & $\begin{array}{c}\text { Estrus } \\
\text { Response }\end{array}$ & $\begin{array}{c}\text { Pregnant at } \\
\text { TAI }(\%)\end{array}$ & $\begin{array}{l}\text { Repeated and re-served } \\
21 \text { d after } 1^{\text {st }} \text { service }(\%)\end{array}$ & $\begin{array}{c}\text { CR after } \\
2^{\text {nd }} \text { service }\end{array}$ & $\begin{array}{l}\text { Overall } \\
\text { CR (\%) }\end{array}$ \\
\hline \multicolumn{7}{|c|}{ Farm } \\
\hline Ovsynch & 7 & $7(100)$ & $3(42.85)$ & 3 & $1(14.28)$ & $4(57.14)$ \\
\hline CIDR alone & 5 & $5(100)$ & $2(40.0)$ & 3 & $2(40.0)$ & $4(80.0)$ \\
\hline CO-Synch + CIDR & 4 & $4(100)$ & $2(50.0)$ & 2 & $2(50.0)$ & $4(100)$ \\
\hline \multicolumn{7}{|c|}{ Field } \\
\hline Ovsynch & 22 & $21(95.45)$ & $7(31.81)$ & 4 & $4(18.18)$ & $11(50.0)$ \\
\hline CIDR alone & 12 & $11(91.66)$ & $3(25.0)$ & 2 & $2(16.66)$ & $5(41.66)$ \\
\hline CO-Synch +CIDR & 18 & $17(94.44)$ & $6(33.33)$ & 3 & $2(11.11)$ & $8(44.44)$ \\
\hline
\end{tabular}

Table 5. Comparison of conception rate at TAI between farm and field conditions during non-breeding season in non-descript heifers.

\begin{tabular}{lcccr}
\hline \multirow{2}{*}{ Treatment } & \multicolumn{2}{c}{ Conception rate (TAI) in heifers (\%) } & \multirow{2}{*}{ Chi sq value } & \multirow{2}{*}{ P value } \\
\cline { 2 - 4 } & Farm & Field & 31.81 & 0.28 \\
Ovsynch & 42.85 & 25.0 & 0.38 & 0.59 \\
CIDR alone & 40.0 & 33.33 & 0.53 & 0.39 \\
CO-Synch +CIDR & 50.0 & 0.53 & \\
\hline
\end{tabular}

Table 6. Estrus response and conception rate (\%) of non-descript cows and heifers in which time of estrus was synchronized with estrus induction protocols during breeding season under field conditions.

\begin{tabular}{|c|c|c|c|c|c|c|}
\hline Protocols & $\begin{array}{l}\text { No. of } \\
\text { Cows }\end{array}$ & $\begin{array}{c}\text { Estrus } \\
\text { Response }\end{array}$ & $\begin{array}{c}\text { Pregnant at } \\
1^{\text {st }} \text { service }\end{array}$ & $\begin{array}{c}\text { Repeated and } \\
\text { re-served } 21 \mathrm{~d} \\
\text { after } 1^{\text {st }} \text { service } \\
(\%)\end{array}$ & $\begin{array}{c}\text { CR after } 2^{\text {nd }} \\
\text { service }\end{array}$ & Overall CR (\%) \\
\hline \multicolumn{7}{|c|}{ Non-Descript Cows } \\
\hline Ovsynch & 53 & $53(100)$ & $25(47.16)$ & 4 & $4(7.54)$ & $29(54.71)$ \\
\hline CIDR alone & 17 & $17(100)$ & $8(47.05)$ & 1 & $1(5.88)$ & $9(52.94)$ \\
\hline $\begin{array}{l}\text { CO-Synch } \\
+ \text { CIDR }\end{array}$ & 19 & $19(100)$ & $9(47.36)$ & 2 & $2(22.22)$ & $11(57.89)$ \\
\hline \multicolumn{7}{|c|}{ Non-Descript Heifers } \\
\hline Ovsynch & 25 & $25(100)$ & $11(44.00)$ & 2 & $1(4.00)$ & $12(48.00)$ \\
\hline CIDR alone & 14 & $12(85.71)$ & $4(28.57)$ & 2 & $1(7.14)$ & $5(35.71)$ \\
\hline $\begin{array}{l}\text { CO-Synch } \\
+ \text { CIDR }\end{array}$ & 13 & $12(100)$ & $6(46.15)$ & 4 & $1(7.69)$ & $7(53.84)$ \\
\hline
\end{tabular}




\section{DISCUSSION}

In Bos indicus cows the rate of estrus detection is usually lower than Bos taurus (Mukasa-Mugerwa, 1989). Therefore, estrus induction treatments which provide either TAI opportunity or insemination after detecting estrus show great potential for the improvement of reproduction efficiency of both dairy and beef cattle. The results revealed that although the tendency for the Ovsynch protocol to be higher in terms of inducing heat and conception rate. The difference among treatment were not significant $(\mathrm{P}>0.05)$ in non-descript cows maintained under farm conditions during the nonbreeding season. The Ovsynch protocol is more efficient in lactating dairy cows than in heifers as ovulation occurred in $85 \%$ of cows and only $54 \%$ of heifers following the first GnRH injection (Pursley et al., 1995). Naikoo et al. (2016) reported that the conception rate at TAI with Ovsynch treatment was $16.66 \%$ however, the conception rate with CIDR treatment was $33.33 \%$. The estrus response $(95.45 \%)$ and conception rate/AI (50\%) with Ovsynch treatment under field conditions in the nondescript indigenous cows was higher than the data reported by Hassan et al. (2017) who showed that the estrus response in Sahiwal cows was $87 \%(40 / 46)$ and the pregnancy rate per AI was $43 \%$ (17/40). The results of estrus response and conception rate achieved by CIDR alone and CO-Synch+CIDR treatments are in harmony with the results of Haider et al. (2017) who reported $82.5 \%$ and $90 \%$ estrus response while pregnancy per AI was $52 \%$ and $58 \%$ in CIDR alone and CIDR along with GnRH treated non-descript cows of Punjab (Pakistan). However, relatively lower conception rates of 26.00 to 42.74 with CIDR were reported by Sathiamoorty and Kathirchelvan (2010) and higher conception rates of 50 to 80 per cent have also been documented by Nakrani et al. (2014) and Dhami et al. (2015) in crossbred cows. Pursley et al. (1997a) observed that the Ovsynch protocol improved the conception rates after TAI by synchronizing ovulation. The lower conception rates at TAI in CIDR inserted groups in this study might be due to the earlier timing of $\mathrm{AI}$ as indicated by our observation of late ovulation time in these cattle in another study through ultrasonography. Therefore, better defining the timing of insemination may increase TAI conception rates. Various factors such as parity, suckling, breed composition, postpartum interval, differences in pasture and diet, BCS and location may affect the success of FTAI protocols (Lamb et al., 2001).

The results revealed that in non-descript heifers although all the protocols were better in terms of inducing heat the CR achieved by using the CIDR device in combination with $\mathrm{GnRH}$ was higher compared to the use of the Ovsynch and CIDR alone protocols during non-breeding season. This might be due to the better control of synchronize of ovulation in heifers using the
CIDR device in TAI protocols. Whereas, the use of the Ovsynch protocol in heifers encountered the problem of heifers exhibiting heat between the GnRH-1 and PGF $2 \alpha$ injections which results in the failure of synchronization of ovulation in all heifers subjected to the TAI protocol. CO-Synch+CIDR protocols inhibit heat and ovulation during the 7 day of CIDR insertion, thereby permitting a $100 \%$ submission rate for FTAI without any effect on fertility. A similar CIDR response was reported with the Ovsynch+CIDR protocol (6 days CIDR period) in Holstein heifers by Rivera et al. (2005). Moreover, Saldarriaga et al. (2007) reported that timed AI pregnancy rates in nulliparous Bos taurus Brahman $\times$ Hereford (F-1) heifers synchronized with COSynch+CIDR was 39.3\%. Larson et al. (2004) found that the pregnancy rate at first service was (53.1\%) in heifers after receiving CO-Synch+CIDR treatment. So, CIDR insertion increased the synchronization rates within the first $3 \mathrm{~d}$ following PGF2 $\alpha$ and resulted in increased pregnancy success. Pursley et al. (1995) reported that in an Ovsynch protocol heifers that could not ovulate following GnRH-2 treatment were reported to be in metestrus or early diestrus stages of the estrus cycle at the time of GnRH-1 treatment. Therefore, ovulation may be poorly synchronized following $\mathrm{PG}$ treatment if the GnRH-1 injection does not ovulate the dominant follicle and therefore fails to synchronize follicular wave emergence.

During the breeding season, the conception rate $(47.19 \%)$ to a single fixed time insemination in the present study was closely corroborated with Gordon et al. (2009) who found that pregnancy rate in synchronized cows was $47.6 \%$ for Ovsynch under control conditions. Similarly, overall conception rate in non-descript cows using CO-Synch+CIDR (57.89\%) was significantly higher $(\mathrm{P}<0.05)$ than CIDR alone $(52.94 \%)$ and Ovsynch $(54.71 \%)$ and this result is supported by different authors (Kim et al., 2005) who reported a pregnancy rate of 52.3 and $53.9 \%$ in Holstein cows treated with CIDR plus GnRH.

In the present study the, CO-Synch+CIDR protocol enhanced the overall conception rate $(53.84 \%)$ in non-descript heifers during the breeding season. Estrada et al. (2002) administered the CO-Synch+CIDR protocol to heifers and obtained a $60 \%$ pregnancy rates. In another study using an AI protocol of GnRH - 7 days PGF2a - 30 to $36 \mathrm{~h}-\mathrm{GnRH}-16$ to $24 \mathrm{~h}$, Pursley et al. (1997b) showed that the pregnancy rate after this treatment was similar to that for the control group (37.8 vs $38.9 \%$ ). All the estrus synchronization protocol used in present study were found to be successful for induction of fertile estrus and improving of the indigenous herd of non-descript cattle by crossing with superior quality bulls through AI even in low breeding season. 
Conclusion: It is concluded that estrus response and conception rates at TAI may be acceptable with the Ovsynch protocol in non-descript cows and with the COSynch+CIDR protocol in non-descript heifers during the non-breeding season. However, conception rates at TAI were satisfactory in all groups under field conditions during the breeding season. So, factors including availability and cost of products, animal confinement and handling will influence the program that will be used. The estrus synchronization protocols may prove to be quite effective in inducing synchronized estrus in non-descript cows and heifers during both the breeding and nonbreeding seasons.

It is recommended that by changing the timing of GnRH-2 and TAI from 48 to 66 or 72 in COSynch+CIDR protocols and 48 to 80 or $92 \mathrm{~h}$ in CIDR alone protocol, increased TAI conception rates can be achieved.

Novelty Statement: Estrus synchronization and timed artificial insemination is unique for the cattle population of Kashmir. Many authors have investigated these estrus synchronization protocols over the past 20 years, rather non-descript cattle have not been studied. Therefore, the research programme has sufficient novelty.

Acknowledgements: This research was supported by a grant from Pak-US Agricultural Linkages Program, Pakistan Agricultural Research Council (PARC), Islamabad. This financial help is gratefully acknowledged.

\section{REFERENCES}

Anzar. M., U. Farooq, M. Mirza, M. Shahab and N. Ahmad (2003). Factors affecting the efficiency of artificial insemination in cattle and buffalo in Punjab, Pakistan. Pakistan Vet. J. 23: 106-113.

Bhoraniya H. L., A. J. Dhami, M. Naikoo, B. C. Parmar and N. P. Sarvaiya (2012). Effect of estrus synchronization protocols on plasma progesterone profile and fertility in postpartum anoestrus Kankrej cows. Trop. Anim. Hlth. Prod. 44: 1191-1197.

Dhami, A. J., B. B. Nakrani, K. K. Hadiya, J. A. Patel and R. G. Shah (2015). Comparative efficacy of different estrus synchronization protocols on estrus induction response, fertility and plasma progesterone and biochemical profile in crossbred anestrus cows. Vet. World. 8: 13101316.

Estrada, A. T., J. Walton, K. Bateman and W. H. Johnson (2002). The effect of estradiol benzoate or GnRH on CIDR-B based synchronization protocols in beef cattle. Proc. Soc. Theriogenology. p. 1.
Gordon, M. B., N. Dinn and R. Rajamahendran (2009). Effects of pre-synchronization and postinsemination treatments on pregnancy rates to a timed breeding Ovsynch protocol in dairy cows and heifers. Can. J. Anim. Sci. 90: 35-44.

Haider M. S., M. Bilal, H. Ahmed, M. Anwar, A. Sattar and S. M. H. Andrabi (2017). Effect of CIDR with or without GnRH and double PGF2 $\alpha$ based estrus synchronization protocols on estrus response and pregnancy per AI in non-descript cows of the Punjab. J. Anim. Plant Sci. 27(4): $1108-1114$

Hassan, M., A. Husnain, M. I. Naveed, U. Riaz and N. Ahmad (2017). Effect of ovsynch versus prostaglandin F2 $\alpha$ protocol on estrus response, ovulation rate, timing of ovulation and pregnancy per artificial insemination in Sahiwal cows. Anim. Sci. J. 88(3): 445-450.

Khan, M. I., S. Jalali, B. Shahid and S. A. Shami (2014). Breeding efficiency of Indigenous $\times$ Jersey, Indigenous $\times$ Jersey $\times$ Friesian crossbred cows at Livestock Development Research Centre, Muzaffarabad, Azad Jammu and Kashmir. Proc. Pakistan Acad. Sci. 51: 289-294.

Khatun, M. A., F. Y. Bari, M. Alam, M. R. Ali and P. K. Sarkar (2014). Post AI Conception Rate in Cattle at Rajarhat, Kurigram, Bangladesh. Wayamba J. Anim. Sci. 6: 845-854.

Kim, U. H., G. H. Suh, H. W. Nam, H. G. Kang and I. H. Kim (2005). Follicular wave emergence, luteal function and synchrony of ovulation following GnRH or estradiol benzoate in a CIDR-treated, lactating Holstein cows. Theriogenology. 63(1): 260-268.

Lamb, C. G., J. S. Stevenson, D. J. Kesler, H. A. Garverick, D. R. Brown and B. E. Salfen (2001). Inclusion of an intravaginal progesterone insert plus GnRH and prostaglandin F $\alpha$ for ovulation control in postpartum suckled beef cows. J. Anim. Sci. 79: 2253-2259.

Lamb, G. C., J. E. Larson, T. W. Geary, J. S. Stevenson, S. K. Johnson, M. L. Day, R. P. Ansotegui, D. J. Kesler, J. M. De-Jarnette and D. G. Landblom (2006). Synchronization of estrus and artificial insemination in replacement beef heifers using gonadotropin-releasing hormone, prostaglandin F2 $\alpha$, and progesterone. J. Anim. Sci. 84: 30003009.

Larson, J. E., G. C. Lamb, T. W. Geary, J. S. Stevenson, S. K. Johnson, M. L. Day, D. J. Kesler, J. M. De Jarnette and D. Landblom (2004). Synchronization of estrus in replacement beef heifers using $\mathrm{GnRH}$, prostaglandin F2 $\alpha$ (PG), and progesterone (CIDR): a multi-location study. J. Anim. Sci. 82(1): 368. 
Layek, S. S., T. K. Mohanty, A. Kumaresan, K. Behera and S. Chand (2011). Behavioural signs of estrus and their relationship to time of ovulation in Zebu (Sahiwal) cattle. Anim. Reprod. Sci. 129(3-4): 140-145.

Mapletoft, R. J., M. F. Martinez, M. G. Colazo and J. P. Kastelic (2003). The use of controlled internal drug release devices for the regulation of bovine reproduction. J. Anim. Sci. 81: 28-36.

Mukasa-Mugerwa, E. (1989). A review of a reproductive performance of female Bos indicus (zebu) cattle, In: ILCA Monograph 6. Ethiopia, ILCA, Addis Ababa.

Naikoo, M., A. J. Dhami and A. Ramakrishnan (2016). Effect of estrus synchronization on plasma progesterone profile and fertility response in postpartum suckled anestrous Kankrej cows. Indian J. Anim. Res. 50(4): 460-465.

Nakrani, B. B., M. T. Panchal, A. J. Dhami, K. K. Hadiya, J. A. Patel, R. K. Gosai and R. G. Shah (2014). Influence of controlled breeding techniques on estrus induction response, conception rate and plasma progesterone profile in anoestrus buffaloes. Glob. J. Med. Res. 14: 16.

Plasse, D., A. C. Warnick and M. Kogar (1970). Reproductive behavior of Bos indicus females in a subtropical environment. IV. Length of estrous cycle, duration of estrus, time of ovulation, fertilization and embryo survival in grade Brahman heifers. J. Anim. Sci. 30: 63-72.

Pursley, J. R., M. O. Mee and M. C. Wiltbank (1995). Synchronization of ovulation in dairy cows using PGF2 $\alpha$ and GnRH. Theriogenology. 44: 915-923.

Pursley, J. R., M. R. Kosorok and M. C. Wiltbank (1997a). Reproductive management of lactating dairy cows using synchronization of ovulation. J. Dairy Sci. 80: 301-306.

Pursley, J. R., M. C. Wiltbank, J. S. Stevensom, J. S. Ottobre, H. A. Barverick and L. L. Andersom (1997b). Pregnancy rates per artificial insemination for cows and heifers inseminated at a synchronized ovulation or synchronized estrus. J. Dairy Sci. 80: 295-300.
Randel, R. D. (1984). Seasonal effects on female reproductive function in the bovine (Indian breeds). Theriogenology. 21: 170-185.

Rivera, H., H. Lopez and P. M. Fricke (2005). Use of intravaginal progesterone releasing inserts in a synchronization protocol before timed $\mathrm{AI}$ and for synchronizing return to estrus in Holstein heifers. J. Dairy Sci. 88: 957-968.

Saldarriaga, J. P., D. A. Cooper, J. A. Cartmill, J. F. Zuluaga, R. L. Stanko and G. L. Williams (2007). Ovarian, hormonal and reproductive events associated with synchronization of ovulation and timed appointment breeding of Bos indicus-influenced cattle using intravaginal progesterone, GnRH and PGF2 $\alpha$. J. Anim. Sci. 85: $151-162$.

Sathiamoorty, T. and M. Kathirchelvan (2010). Efficacy of PGF2 $\alpha$, CIDR and Ovsynch treatment on estrus response and fertility rate in crossbred cows. Indian J. Anim. Reprod. 31: 43-45.

Senthilkumar, K. and C. Chandrahasan (2015). Oestrus behaviour in natural and induced oestrum in dairy cattle by PGF $2 \alpha$ with GnRH and hCG. International J. Science. Environment and Technology. 4(1): 243-247.

Stahringer, R. C., D. A. Neuendorff and R. D. Randel (1999). The effect of aspirin administration and parity on plasma salicylate concentrations and postpartum reproductive parameters in Brahman cows. Prostaglandins. 58: 125.

Stevenson, J. S., S. L. Pulley and H. I. Jr Mellieon (2012). Prostaglandin F2 $\alpha$ and gonadotropinreleasing hormone administration improve progesterone status, luteal number, and proportion of ovular and anovular dairy cows with corpora lutea before a timed artificial insemination program. J. Dairy Sci. 95: 18311844.

Wildman, E.E., G.M. Jones, P.E. Wagner, and R.L. Bowman (1982). A dairy cow body condition scoring system and its relationship to selected production characteristics. J. Dairy Sci. 65(3): 495-501. 